\title{
New Melting Data of the Two Polymorphs of Prednisolone
}

\author{
Yohann Corvis, ${ }^{\dagger}$ Philippe Négrier, ${ }^{\ddagger}$ Jérémie Soulestin, $^{\S}$ and Philippe Espeau* ${ }^{\dagger}$ \\ †Unité de Technologies Chimiques et Biologiques pour la Santé, Inserm U 1022 CNRS UMR 8258, Faculté des Sciences \\ Pharmaceutiques et Biologiques, Université Paris Descartes, Sorbonne Paris Cité, 4 avenue de l'Observatoire, 75006 Paris, France \\ ${ }^{\ddagger}$ Laboratoire Ondes et Matière d’Aquitaine, Université de Bordeaux, UMR CNRS 5798, 351 cours de la Libération, 33405 Talence \\ Cedex, France \\ ${ }^{\S}$ Mines Douai, Department of Polymers and Composites Technology and Mechanical Engineering, 941 rue Charles Bourseul, CS \\ 10838, 59508 Douai, France
}

\begin{abstract}
Prednisolone is known to exist in two anhydrous solid polymorphic forms. The substance is known to degrade upon melting, resulting in erroneous melting data, as shown by the widely scattered results reported in the literature. In this article, thermal analyses carried out at different scan rates show that the onset temperature and the enthalpy value of the signal increase with the scan rate and reach plateau values for high scan rates.

Owing to flash scanning calorimetry, the plateau value for the temperature has been identified as the "true" temperature of melting of both polymorphs. This consistent set of new thermodynamic data on the two solid forms leads to the conclusion that both forms are unambiguously enantiotropes of each other. The solid-solid transition has been observed experimentally for the first time and has been confirmed by calculation.
\end{abstract}

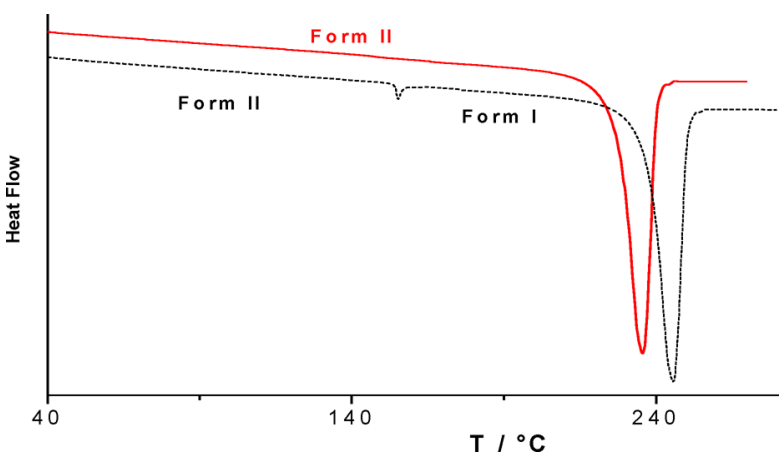

\section{INTRODUCTION}

Prednisolone is a corticosteroid used to treat a number of conditions, such as inflammation, allergies, asthma, and vision problems. This drug is available in different forms such as solution, tablet, syrup, suspension, or liquid.

Anhydrous prednisolone is known to exist in two crystal modifications. Forms I and II crystallize respectively into the monoclinic and the orthorhombic crystal systems. ${ }^{1}$ From thermal analysis experiments, it was found that Form I melts at a higher temperature (between 236.5 and $239.0^{\circ} \mathrm{C}$ ) with a higher melting entropy than Form II (between 223.8 and 227.7 $\left.{ }^{\circ} \mathrm{C}\right)$. The authors from ref 1 then concluded that both forms behave enantiotropically at ordinary pressures with a transition point estimated between 120 and $130{ }^{\circ} \mathrm{C}$, but were never experimentally observed. Form II is thus the thermodynami cally most stable form at room temperature and Form I the most stable polymorph above the transition point. Prednisolone is reported to degrade upon melting, ${ }^{2}$ as evidenced by both mass and heat flow vs temperature curves, thermogravimetric analysis (TGA) and differential scanning calorimetry (DSC) curves, respectively. The DSC peak shapes are very rough during and after melting of the two forms ${ }^{1,3}$ and an important weight loss is visible during melting. ${ }^{1,3}$ It was previously proved that degradation occurring upon melting is favored when DSC experiments are carried out at low scan rates. ${ }^{4,5}$ This is the reason why the melting temperature as well as the associated enthalpy of prednisolone polymorphs are most of the time given within a large interval of values, but not as well defined values. ${ }^{1,2,6}$ It is therefore certain that the integration of the apparent melting peaks provides erroneous melting enthalpy. In order to avoid degradation upon melting, it was previously shown that DSC analysis has to be carried out at high scanning rate. $^{4,5}$

In the present article, Forms I and II were analyzed by conventional DSC experiments with heating rates ranging from 2 to $60{ }^{\circ} \mathrm{C} \cdot \mathrm{min}^{-1}$, to propose accurate values for temperatures and enthalpies of melting, based on previous protocol experiments established for ascorbic acid ${ }^{4}$ and $p$ synephrine. The melting temperature of both solid forms were also determined by flash DSC (FDSC) and compared to the values obtained by conventional DSC.

\section{EXPERIMENTAL SECTION}

The differential scanning calorimetry (DSC) and thermogravi metric analysis (TGA) experiments were performed using two devices, namely DSC 822e and a TGA/DSC 1 from Mettler Toledo (Switzerland), under nitrogen gas. Indium and Zinc (99.9\% of purity) were used for temperature and enthalpy calibration of the DSC device. The DSC experiments were carried out at different scan rates from 5 to $60^{\circ} \mathrm{C} \cdot \mathrm{min}^{-1}$. 
Table 1. Temperatures and Enthalpies of Melting of Two Polymorphs of Prednisolone Obtained from DSC Experiments Collected in the Literature and from This Work

\begin{tabular}{|c|c|c|c|c|c|}
\hline \multirow[b]{2}{*}{ ref. } & \multicolumn{2}{|c|}{ Form I } & \multicolumn{2}{|c|}{ Form II } & \multirow[b]{2}{*}{ scan rate $\left({ }^{\circ} \mathrm{C} \min ^{-1}\right) \Delta$} \\
\hline & $T_{\text {fus }}\left({ }^{\circ} \mathrm{C}\right)$ & $\Delta_{\text {fus }} H\left(\mathrm{~kJ} \mathrm{~mol}^{-1}\right)$ & $T_{\text {fus }}\left({ }^{\circ} \mathrm{C}\right)$ & $\Delta_{\text {fus }} H\left(\mathrm{~kJ} \mathrm{~mol}^{-1}\right)$ & \\
\hline 1 & 236.5239 .0 & $26.5 \quad 29.7$ & $223.8 \quad 227.7$ & $34.37 \quad 35.80$ & 4 \\
\hline 2 & $230 \quad 236$ & & $220 \quad 227$ & & 20 \\
\hline 3 & $243.0 / 245.3$ & $23.67 / 28.08$ & 239.1 & 33.14 & 2 \\
\hline 6 & $218 \quad 234$ & & $210 \quad 225$ & & 4 \\
\hline 6 & $230 \quad 244$ & & 220236 & & 10 \\
\hline 12 & 241.8 & & 235.3 & & 5 \\
\hline this work & $256.7 \pm 0.9$ & $39.9 \pm 0.3$ & $249.3 \pm 0.8$ & $42.6 \pm 0.5$ & 260 \\
\hline
\end{tabular}

FDSC experiments were carried out with a Mettler Toledo Flash DSC1 at a heating rate of $1000 \mathrm{~K} \cdot \mathrm{s}^{-1}$. The measuring cell was continuously flushed with nitrogen gas. High purity indium was used for temperature calibration of the sensor. A small crystal of a few tens of nanograms was placed under a microscope directly on the active area of the sensor, which is circular with a $500 \mu \mathrm{m}$ diameter. Although such a sample mass cannot be directly determined by weighing, one can never theless have access to this parameter by comparing a given heat of fusion obtained with the FDSC to the corresponding one measured with a conventional DSC device. ${ }^{7}$ The standard uncertainties on the temperature and enthalpy data were determined from the standard deviation of three independent measurements.

$\mathrm{X}$ ray powder diffraction profiles were recorded using a high resolution INEL diffractometer equipped with a CPS (curve position angular sensitive detector) 120 position sensitive multi detector (Debye-Scherrer geometry, transmission mode, $\mathrm{Cu} \mathrm{K} \alpha_{1}$ radiation $\left.(\lambda=1.5406 \AA)\right)$.

Crystal structure was determined with the reflex plus module of Materials Studio Modeling 5.5. ${ }^{8}$ First, the pattern was indexed by means of the peak picking option of the software package. Potential solutions for cell parameters and space group were found using the $\mathrm{X}$ cell algorithm. ${ }^{9}$ Then, a Pawley profile fitting procedure was applied including refined cell parameters experimental profile fitting with pseudovoigt function, zero shift, and asymmetry Finger Cox Jephcoat function. ${ }^{10}$ The structure refinement was achieved using the Rietveld method, rigid body molecular units, overall isotropic factor, and March Dollase preferred orientations. ${ }^{11}$

Saturated solutions of commercial prednisolone (Form I) were placed in pierced containers at room temperature to favor very slow evaporation of the solvents. Crystals of Form I grew after ethanol or acetone evaporation and crystals of Form II after anhydrous methanol evaporation.

\section{RESULTS AND DISCUSSION}

If we analyze the reported melting data of prednisolone Forms I and II (Table 1), many contradictions exist for both temperatures and enthalpies of melting. If we refer to Table 1 , and more particularly to the results from ref 6 , one can observe that the melting domains overlap, and then it becomes difficult to conclude safely that Form I melts at a temperature higher than that of Form II. Indeed, the order of stability could be inverted. In other words, no conclusions can actually be drawn from these conflicting values. In all reported cases, the II-I o $r$ I -II transition point has never been observed. This questioned the enantiotropic behavior of the system.

The second observation from Table 1 concerns the disparity of the results reported. This leads to the conclusion that the temperatures and enthalpies of melting of the two solid forms are in fact not precisely known.

First, the XRPD patterns of the two polymorphs of prednisolone were recorded at room temperature $(295 \mathrm{~K}$ for Form I and $298 \mathrm{~K}$ for Form II). The cell and space groups were found to match with the ones previously reported from crystal structure determination on single crystal at $220 \mathrm{~K}^{1}$ Form I crystallizes in the monoclinic $\mathrm{P} 2{ }_{1}$ space group and Form II in the orthorhombic $P 2_{1} 2_{1} 2_{1}$ space group. The cell parameters best reproducing the diffraction patterns at room temperature are given in Table 2. As observed, they agree with the

Table 2. Unit Cell Parameters for Prednisolone Forms I and II Obtained from XRPD (Including This Work) and Single Crystal

\begin{tabular}{lllll} 
& reference & \multicolumn{1}{c}{ this work } & \multicolumn{1}{c}{13} & \multicolumn{1}{c}{1} \\
& $T(\mathrm{~K})$ & $295(1)$ & $\mathrm{RT}$ & $220(2)$ \\
& $a(\AA)$ & $6.3470(9)$ & $6.350(3)$ & $6.3052(5)$ \\
Form I & $b(\AA)$ & $12.9981(16)$ & $12.985(8)$ & $12.9392(7)$ \\
& $c(\AA)$ & $10.9844(15)$ & $10.971(9)$ & $10.9984(9)$ \\
& $\beta($ deg.) & $91.176(9)$ & $91.24(5)$ & $91.167(9)$ \\
& $V\left(\AA^{3}\right)$ & $906.0(2)$ & $906.0(1)$ & $897.11(12)$ \\
& $T(\mathrm{~K})$ & $298(1)$ & $\mathrm{RT}$ & $220(2)$ \\
& $a(\AA)$ & $6.0133(9)$ & $6.009(2)$ & $5.9774(3)$ \\
Form II & $b(\AA)$ & $11.7949(13)$ & $11.808(7)$ & $11.7916(7)$ \\
& $c(\AA)$ & $25.588(4)$ & $25.643(12)$ & $25.5228(14)$ \\
& $V\left(\AA^{3}\right)$ & $1814.9(4)$ & $1819(3)$ & $1798.93(17)$ \\
\hline
\end{tabular}

previously reported ones at room temperature. The expansion of the unit cell remains very low with temperature. Indeed, the cell volume increases only about $1 \%$ between $220 \mathrm{~K}$ and room temperature. The already published conformations of the molecules ${ }^{1}$ were taken as the starting point to refine the structures at room temperature. The final Rietveld refinements converged to a final Rwp value of $7.42 \%$ for Form I and 5.06\% for Form II (Figure 1).

The commercial prednisolone Form I was examined by DSC at various heating rates from 2 to $60^{\circ} \mathrm{C} \cdot \mathrm{min}^{-1}$. At low heating rate, i.e., $5{ }^{\circ} \mathrm{C} \cdot \mathrm{min}^{-1}$, degradation is confirmed upon melting (Figure 2) whereas, for a heating rate of $60{ }^{\circ} \mathrm{C} \cdot \mathrm{min}^{-1}$, the degradation can be bypassed during melting and manifests itself later.

As shown in Figure 3, the melting temperature as well as the melting enthalpy of Form I increase with the DSC heating rate. This dependence was previously reported ${ }^{6}$ but is in contra diction with the conclusion of Veiga et al. ${ }^{3}$ Both parameters reach a plateau value at high heating rates. The melting temperature of Form I could therefore be extrapolated from this plateau at $256.7 \pm 0.9{ }^{\circ} \mathrm{C}$ ( Figure 3A, Table 1), much 

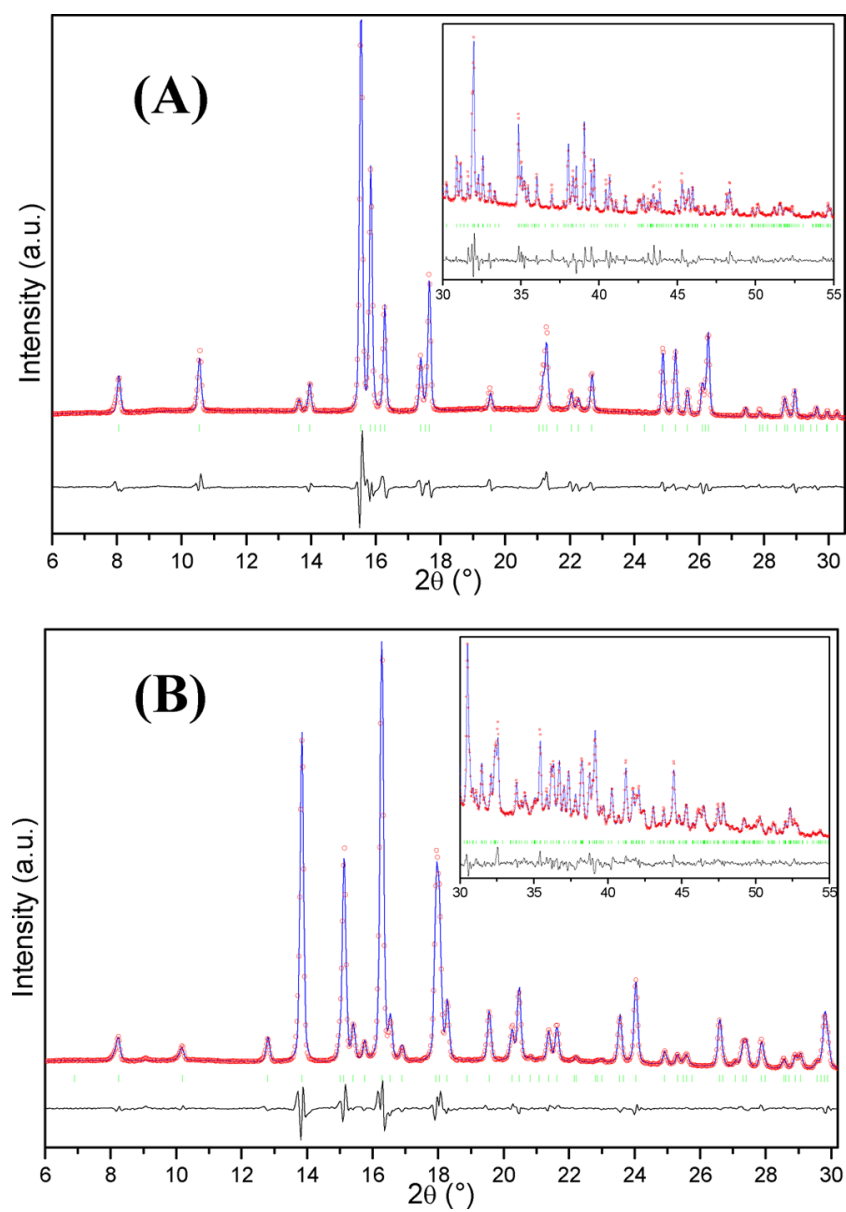

Figure 1. Rietveld refinement of $\mathrm{X}$ ray diffraction patterns of the two polymorphs of prednisolone obtained at RT. (A): Form I; (B): Form II. Blue line: experimental pattern; empty red circles: calculated pattern; green vertical bars: peak positions; black line: residual XRPD patterns. The insert corresponds to the scale for the data between 30 and 55 deg. magnified 8 times for Panel A and 14 times for Panel B.

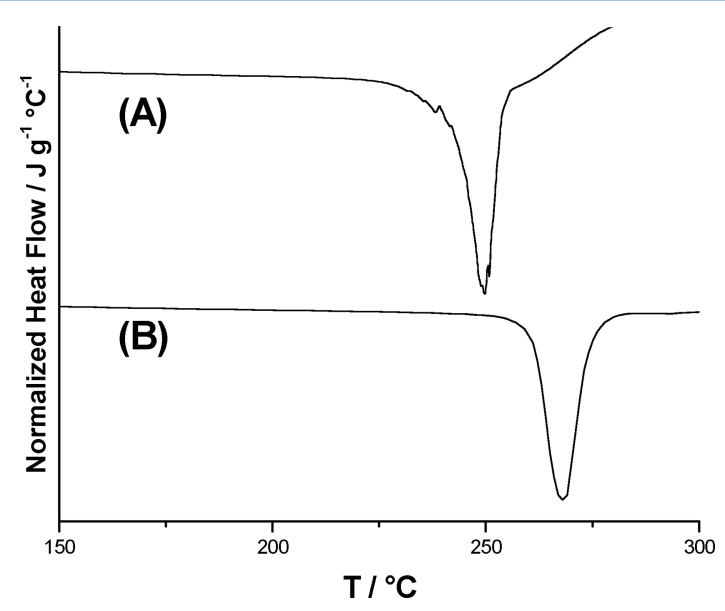

Figure 2. Normalized DSC curves of prednisolone Form I obtained for two heating rates: (A) $5{ }^{\circ} \mathrm{C} \cdot \mathrm{min}^{-1}$ and (B) $60{ }^{\circ} \mathrm{C} \cdot \mathrm{min}^{-1}$.

much higher than the literature values. As far as the melting enthalpy is concerned, the plateau is reached for a value of 110.8 $\pm 0.9 \mathrm{~J} \cdot \mathrm{g}^{-1}\left(39.9 \pm 0.3 \mathrm{~kJ} \cdot \mathrm{mol}^{-1}\right)$ as shown in Figure $3 \mathrm{~B}$ and gathered in Table 1 . This value is, on average, $10 \mathrm{~kJ} \cdot \mathrm{mol}^{-1}$ higher than the literature data. As previously demonstrated for other
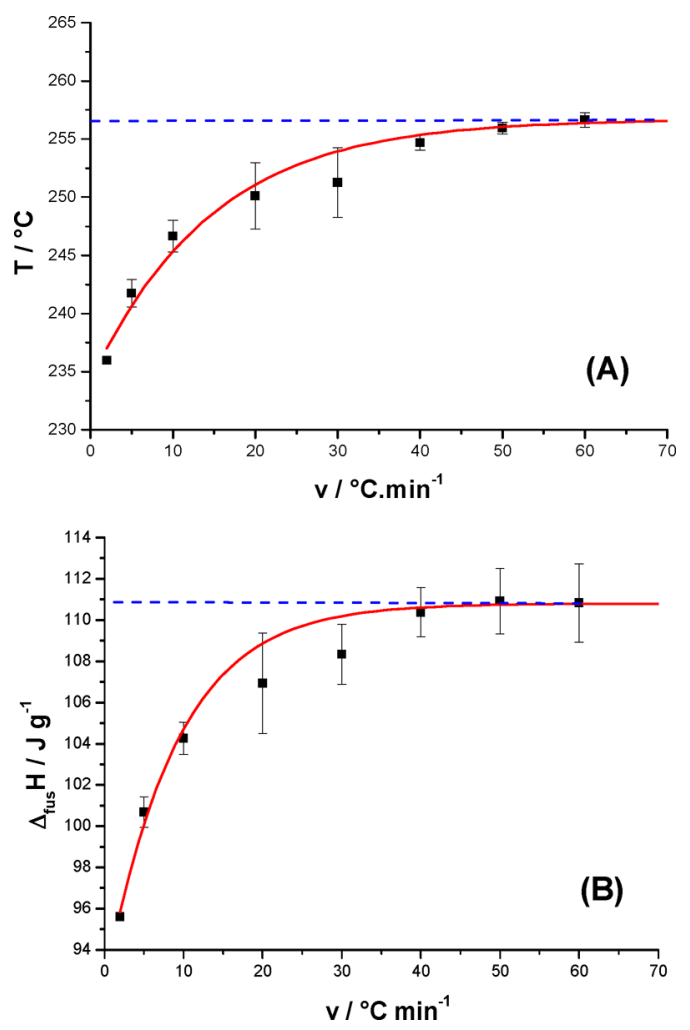

Figure 3. Temperature (A) and enthalpy (B) of melting of prednisolone Form I obtained from DSC measurements at different scan rates.

substances degrading upon melting, ${ }^{4,5}$ the degradation has been bypassed for high DSC scanning rates, giving access to only the melting of prednisolone, the degradation process being shifted to higher temperatures. Owing to this approach, the so obtained values, both for temperature and enthalpy, can be assimilated to true melting data.

The same protocol was followed for prednisolone Form II. The melting temperature of Form II can be determined by extrapolation at $249.3 \pm 0.8{ }^{\circ} \mathrm{C}$ from Figure $4 \mathrm{~A}$ and the melting enthalpy can be obtained at the plateau value of $118.1 \pm 1.3 \mathrm{~J} \cdot \mathrm{g}$ ${ }^{-1}\left(42.6 \pm 0.5 \mathrm{~kJ} \cdot \mathrm{mol}^{-1}\right)$ from Figure 4B. These values are gathered in Table 1 . As for Form I and for the same reasons, the so obtained data are higher than the literature data determined at lower DSC scan rates.

In order to confirm these results, the melting points of both solid forms of prednisolone were examined by FDSC with a heating rate of $1000 \mathrm{~K} \mathrm{~s}^{-1}$ (Figure 5). The melting temperature of Forms I and II were found to be respectively $257 \pm 2{ }^{\circ} \mathrm{C}$ and $248 \pm 2{ }^{\circ} \mathrm{C}$. These values are in very good agreement with the values determined from the previous graphs. Moreover, previous investigations carried out by FDSC at different scan rates, with Form I and with the sesquihydrate of prednisolone, led to a melting temperature of Form I located between 250 and $260{ }^{\circ} \mathrm{C}$. $^{14}$

Form II melts at a lower temperature but with a higher enthalpy than Form I. This confirms that both polymorphs are enantiotropically related, ${ }^{1,15}$ and that a II-I transition point should exist. In order to evaluate the temperature and the enthalpy of this II-I transition point, based on the first principle of thermodynamics, a Hess cycle is applied, assuming the $\mathrm{Cp}$ variations between the solid and the liquid states are negligible in the considered temperature range. Hence: 

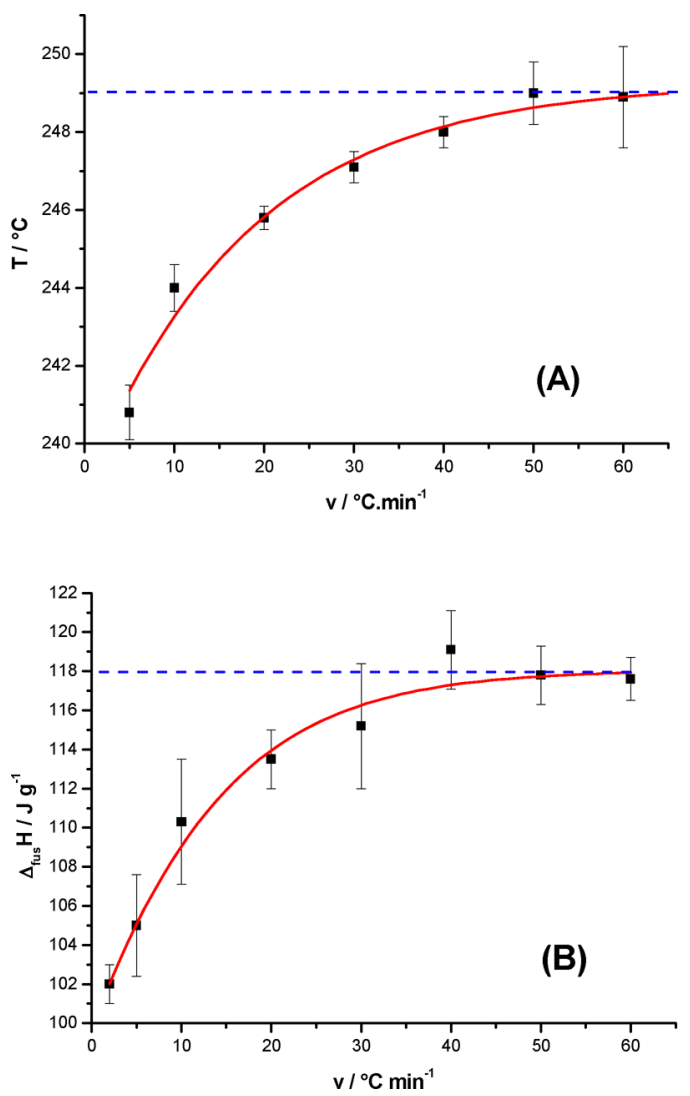

Figure 4. Temperature (A) and enthalpy (B) of melting of prednisolone Form II obtained from DSC measurements at different scan rates.

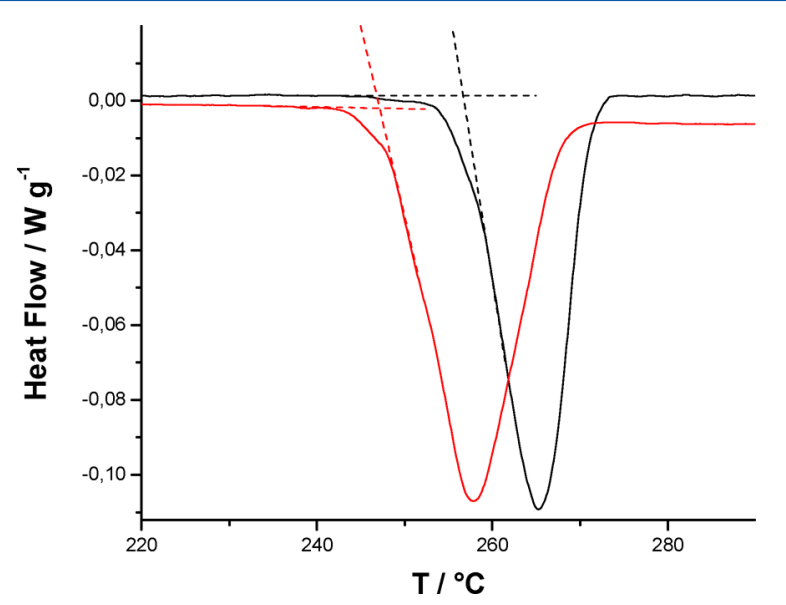

Figure 5. Normalized FDSC curves of Form I (black curve) and Form II (red curve) of prednisolone obtained at a $1000 \mathrm{~K} \mathrm{~s}^{-1}$ scan rate.

$$
\begin{aligned}
& \Delta_{\text {trans }} H\left(\mathrm{II}-\mathrm{I}, T_{\text {trans }}(\mathrm{II}-\mathrm{I})\right) \\
& \quad=\Delta_{\text {fus }} H\left(\mathrm{II}, T_{\text {fus }}(\mathrm{II})\right)-\Delta_{\text {fus }} H\left(\mathrm{I}, T_{\text {fus }}(\mathrm{I})\right) \\
& \begin{array}{l}
\Delta_{\text {trans }} H\left(\mathrm{II}-\mathrm{I}, T_{\text {trans }}(\mathrm{II}-\mathrm{I})\right) \\
\quad=118.1-110.8 \\
=7.3 \pm 2.2 \mathrm{Jg}^{-1}
\end{array}
\end{aligned}
$$

The latter standard uncertainty was obtained by summing the standard uncertainty related to the heat of fusion of Form I, on the one hand, with the one related to heat of fusion of Form II, on the other hand.

Since no data are reported for this transition enthalpy, no further comparison is possible.

Regarding the entropy variation, we can also apply that

$$
\begin{aligned}
& \frac{\Delta_{\text {trans }} H\left(\mathrm{II}-\mathrm{I}, T_{\text {trans }}(\mathrm{II}-\mathrm{I})\right.}{T_{\text {trans }}(\mathrm{II}-\mathrm{I})} \\
& =\frac{\Delta_{\text {fus }} H\left(\mathrm{II}, T_{\text {fus }}(\mathrm{II})\right)}{T_{\text {fus }}(\mathrm{II})}-\frac{\Delta_{\text {fus }} H\left(\mathrm{I}, T_{\text {fus }}(\mathrm{I})\right)}{T_{\text {fus }}(\mathrm{I})}
\end{aligned}
$$

Thus, we obtain $T_{\text {trans }}(\mathrm{II}-\mathrm{I})=157.9 \pm 1.9{ }^{\circ} \mathrm{C}$.

It is noteworthy that the standard uncertainty given for $T_{\text {trans }}$ (II-I) was determined by means of the differential of the logarithm entropy variation equation, all the other standard uncertainties already being determined.

This value is slightly higher than the one reported by Suitchmezian et al., who estimated the transition between 120 and $130{ }^{\circ} \mathrm{C} .{ }^{1}$

Surprisingly and in a random manner, some DSC curves carried out on prednisolone Form II revealed a small endothermic peak at around $154{ }^{\circ} \mathrm{C}$, as shown in Figure 6

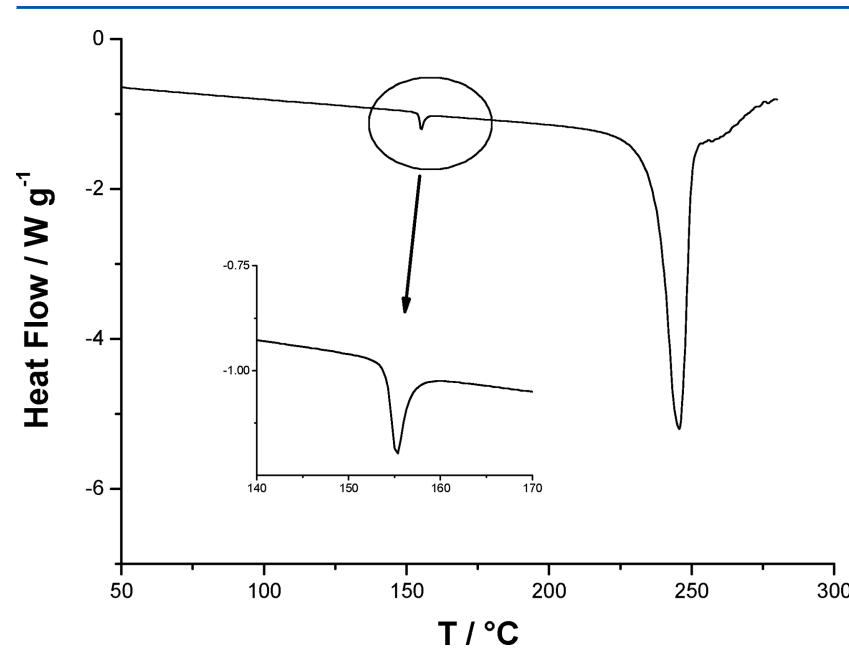

Figure 6. DSC curve of prednisolone Form II (recrystallized from anhydrous methanol) at a $20{ }^{\circ} \mathrm{C} \cdot \mathrm{min}^{-1}$ heating rate.

for a scan rate of $20{ }^{\circ} \mathrm{C} \cdot \mathrm{min}^{-1}$. Consistent with the above calculation, this signal could be associated with the II-I transition point. The associated enthalpy was found to be $1.3 \mathrm{~J}$. $\mathrm{g}^{-1}$, much lower than the calculated one $\left(7.3 \mathrm{~J} \cdot \mathrm{g}^{-1}\right)$. This suggests that the II-I transformation is not complete, as confirmed by the onset temperature of the melting peak close to $245{ }^{\circ} \mathrm{C}$. This temperature, if we refer to Figures $2 \mathrm{~A}$ and $3 \mathrm{~A}$, corresponds to the melting point of Form II for a scanning rate of $20{ }^{\circ} \mathrm{C} \mathrm{min}^{-1}$.

\section{CONCLUSION}

The implementation of the "DSC method", previously developed to determine the true melting data of ascorbic acid and $p$ synephrine, ${ }^{4,5}$ was applied here in the case of the two polymorphic forms of prednisolone. The melting temperatures, determined from the plateau values, were finally corroborated by flash scanning calorimetry experiments. For the first time, the solid-solid transition between Form II and Form I has been observed by DSC at a temperature close to the calculated one $\left(\sim 155{ }^{\circ} \mathrm{C}\right)$. This matching in temperature allows the 
identification of this signal, even if the nature of the phase obtained after crossing this endothermic peak has not been identified yet. However, the reason why this transition occurs occasionally still remains to be understood. Based on these new findings, it can be concluded without any doubt that the two anhydrous polymorphic forms of prednisolone exhibit an enantiotropic relationship under ordinary pressure.

\section{AUTHOR INFORMATION}

\section{Corresponding Author}

*Telephone: (33) 1537396 76; E mail: philippe.espeau@ parisdescartes.fr.

\section{Notes}

The authors declare no competing financial interest.

\section{ACKNOWLEDGMENTS}

This work was financially supported by the ANR project NPLIN 4 drug including a 1 year postdoctoral position of Camille Alzina. The authors thank the latter for her contribution to the experimental work. Thanks are also due to Ms. K. Debbasch for her advice on the manuscript.

\section{REFERENCES}

(1) Suitchmezian, V.; Jess, I.; Sehnert, J.; Seyfarth, L.; Senker, J.; Näther, C. Structural, Thermodynamic, and Kinetic Aspects of the Polymorphism and Pseudopolymorphism of Prednisolone $(11,17 \alpha, 21$ Trihydroxy 1,4 pregnadien 3,20 dion). Cryst. Growth Des. 2008, 8, 98-107.

(2) de Maury, G.; Chauvet, A.; Terol, A.; Masse, J. Etude Thermoanalytique de Quelques Steroïdes. IV. Prednisolone et Dérivés. Thermochim. Acta 1986, 97, 127-142.

(3) Veiga, M. D.; Cadorniga, R.; Lozana, R. Thermal Study of Prednisolone Polymorphs. Thermochim. Acta 1985, 96, 111-115.

(4) Corvis, Y.; Menet, M. C.; Négrier, P.; Lazerges, M.; Espeau, P. The Role of Stearic Acid in Ascorbic Acid Protection from Degradation: a Heterogeneous System for Homogeneous Thermody namic Data. New J. Chem. 2013, 37, 761-768.

(5) Rosa, F.; Négrier, P.; Corvis, Y.; Espeau, P. Crystal Structure Determination and Thermal Behavior Upon Melting of $\mathrm{p}$ Synephrine. Thermochim. Acta 2016, 632, 18-22.

(6) Kuhnert Brandstätter, M.; Gasser, P. Solvates and Polymorphic Modifications of Steroid Hormones. II. Microchem. J. 1971, 16, 577589.

(7) Corvis, Y.; Wurm, A.; Schick, C.; Espeau, P. New Menthol Polymorphs Identified by Flash Scanning Calorimetry. CrystEngComm 2015, 17, 5357-5359.

(8) Materials Studio Modeling 5.5. http://accelrys.com/products/ collaborative science/biovia materials studio/.

(9) Neumann, M. A. X Cell: A Novel Indexing Algorithm for Routine Tasks and Difficult Cases. J. Appl. Crystallogr. 2003, 36, 356-365.

(10) Pawley, G. S. Unit Cell Refinement from Powder Diffraction Scans. J. Appl. Crystallogr. 1981, 14, 357-361.

(11) Dollase, W. A. Correction of Intensities for Preferred Orientation in Powder Diffractometry: Application of the March Model. J. Appl. Crystallogr. 1986, 19, 267-272.
(12) Nishiwaki, A.; Watanabe, A.; Higashi, K.; Tozuka, Y.; Moribe, K.; Yamamoto, K. Molecular States of Prednisolone Dispersed in Folded Sheet Mesoporous Silica (FSM 16). Int. J. Pharm. 2009, 378, $17-22$.

(13) Saindon, P. J.; Cauchon, N. S.; Sutton, P. A.; Chang, C. J.; Peck, G. E.; Byrn, S. R. Solid State Nuclear Magnetic Resonance (NMR) Spectra of Pharmaceutical Dosage Forms. Pharm. Res. 1993, 10, 197203.

(14) Corvis, Y.; Wurm, A.; Schick, C.; Espeau, P. Vitreous State Characterization of Pharmaceutical Compounds Degrading upon Melting by Using Fast Scanning Calorimetry. J. Phys. Chem. B 2015, $119,6848-6851$

(15) Burger, A.; Ramberger, R. On the Polymorphism of Pharmaceuticals and Other Molecular Crystals. I Theory of Thermodynamic Rules. Microchim. Acta 1979, 72, 259-271. 